\title{
Insights from the Greek experience of the use of Blinatumomab in pediatric relapsed and refractory acute lymphoblastic leukemia patients
}

\author{
M. AMPATZIDOU ${ }^{1, *}$, A. KATTAMIS ${ }^{2}$, M. BAKA ${ }^{3}$, G. PATERAKIS ${ }^{4}$, T. ANASTASIOU ${ }^{5}$, M. TZANOUDAKI ${ }^{6}$, A. KAISARI ${ }^{7}$, G. AVGERINOU $^{2}$, \\ D. DOGANIS ${ }^{3}$, V. PAPADAKIS ${ }^{1}$, V. KITRA ${ }^{7}$, S. POLYCHRONOPOULOU ${ }^{1}$ \\ ${ }^{1}$ Department of Pediatric Hematology-Oncology, Aghia Sophia Children's Hospital, Athens, Greece; ${ }^{2}$ First Department of Pediatrics, Aghia So- \\ phia Children's Hospital, National and Kapodistrian University of Athens, Athens, Greece; ${ }^{3}$ Oncology Department, P. and A. Kyriakou Children's \\ Hospital, Athens, Greece; ${ }^{4}$ Immunology Laboratory, Department of Flow Cytometry, G. Gennimatas General Hospital, Athens, Greece; ${ }^{5}$ Hema- \\ tology Laboratory, P. and A. Kyriakou Children's Hospital, Athens, Greece; ' Immunology Laboratory, Aghia Sophia Children's Hospital, Athens, \\ Greece; ${ }^{7}$ Bone Marrow Transplantation Unit, Aghia Sophia Children's Hospital, Athens, Greece
}

${ }^{*}$ Correspondence: mirellaaba@yahoo.gr

Received January 28, 2020/ Accepted April 29, 2020

\begin{abstract}
Pediatric refractory or relapsed acute lymphoblastic leukemia (ALL) poses unique therapeutic challenges, with novel immunotherapy approaches offering potential cure opportunities. In this frame, the use of Blinatumomab may induce durable remissions, serving as a successful bridge to allogeneic hematopoietic stem cell transplantation (allo-HSCT). Herein, we retrospectively summarize the Greek experience on pediatric relapsed/refractory B-cell precursor ALL patients that were treated with Blinatumomab in a compassionate, off-label setting as an effort to achieve disease clearance and proceed to allo-HSCT. In our cohort of 9 patients, 6/9 (66.7\%) responded to Blinatumomab, achieving complete morphological remission (CR) after the 1st cycle, while minimal/measurable residual disease (MRD)-negativity $\left(<10^{-4}\right)$ after the 1 st cycle was achieved in $2 / 2$ patients (100.0\%) with prior CR. A successful bridge to HSCT was feasible in $5 / 9$ patients (55.6\%). Median relapse-free survival (RFS) was 3.0 months (range 0.5-21.4 months) and median overall survival (OS) was 8.7 months (range 1.4-47.1 months) for the whole pediatric cohort. There was a trend of prolonged survival among patients who achieved MRD response after the 1st Blinatumomab administration. MRD response (defined as the $>=2-\log$ reduction of MRD value before and after Blinatumomab administration), was associated with a median RFS/OS of 7.4/7.6 months, while lack of MRD response was associated with a median RFS/OS of 0.5/3.0 months, respectively. Novel therapeutic maneuvers, in order to overcome disease resistance, i.e. increased usage of Blinatumomab dose $\left(45 \mu \mathrm{g} / \mathrm{m}^{2} /\right.$ day $)$, combination with donor lymphocyte infusions (DLIs), use of other immunotherapy salvage approaches (inotuzumabozogamicin), are herein discussed. Additionally, the optimal number of Blinatumomab cycles, the CD19-negative relapses and lineage switch, are also addressed. Our data although referred to a limited, however refractory or relapsed and heavily pretreated number of patients, strongly suggest that Blinatumomab may well induce sustained remissions and serve as an effective bridge to HSCT. Whether immunotherapy combined with chemotherapy can outweigh the need for subsequent allo-HSCT, if incorporated into frontline high-risk ALL therapy, remains an optimistic issue to be verified in future randomized clinical trials.
\end{abstract}

Key words: Blinatumomab, refractory or relapsed acute lymphoblastic leukemia (ALL), HSCT, immunotherapy

Relapsed or refractory B-cell precursor (Bcp) acute lymphoblastic leukemia (ALL) is associated with dismal outcome and resistance to intensive chemotherapy regimens and poses unique therapeutic challenges [1-9]. In the pediatric setting, novel immunotherapy approaches offer potential cure opportunities, inducing remission, mediating a successful bridge to allogeneic hematopoietic stem cell transplantation (allo-HSCT) [1-8].

Pediatric Bcp ALL, characterized by stable and sufficient expression of CD19, represents an excellent target for immunotherapeutic approaches, providing an ideal model for immunotherapy salvage treatment with outstanding efficacy and accepted toxicity profile $[1,2,5,6]$. Blinatumomab is a first-in-class bispecific T-cell engager (BiTE) antibody construct that selectively binds with high affinity to the cluster of differentiation (CD) 19 (expressed on tumor cells of B-cell lineage) and CD3 (expressed on T cells). Blinatumomab's innovative mechanism of action utilizes the patient's own cytotoxic T cells to attack the CD19-positive leukemia cells, inducing disease clearance and offering patients with poor outcome a transplant opportunity that will, potentially, improve survival rates [1-3]. 
In this report, we present clinical data of a Greek pediatric group of relapsed and refractory Bcp ALL patients that were treated with Blinatumomab, as a salvage treatment, in a compassionate, off-label setting and in an effort to achieve disease clearance and proceed to subsequent alloHSCT. This is the first retrospective study from Greece to report and analyze the results of the compassionate use of Blinatumomab in all the Greek Departments of PediatricHematology-Oncology. Apart from efficacy, response rates, survival, and MRD kinetics, additional issues addressed and highlighted in the current study are novel therapeutic maneuvres. These include combination with donor lymphocyte infusions (DLIs), increased Blinatumomab dose (45 $\mu \mathrm{g} / \mathrm{m}^{2} /$ day) in order to overcome disease ongoing resistance, as well as other immunotherapy salvage approaches (inotuzumab ozogamicin). Additionally, the optimal number of Blinatumomab cycles, CD19-negative relapses, and lineage switch are also addressed. A correlation and clinical estimation of survival rates and outcome of historical controls of a Greek pediatric group of relapsed/refractory patients that have been diagnosed and treated before the Blinatumomab era (2000-2015), in one Center, is also presented.

\section{Patients and methods}

Patients. In the reported pediatric cohort, patients treated with Blinatumomab received immunotherapy in a compassionate, off-label setting and were not enrolled in a certain clinical study. Pediatric patients $<18$ years with refractory or relapsed Bcp ALL who consistently expressed CD19 were considered eligible for Blinatumomab treatment. The disease was either primary refractory, or in the first relapse following full salvage induction regimen, in second or later relapse, or in any relapse after allo-HSCT. All included patients were treated in the 3 Pediatric Hematology-Oncology Departments and the Bone Marrow Transplantation Unit (BMT), located in the ELPIDA Oncology wing of the "Aghia Sophia" Children's Hospital in Athens, Greece. Blinatumomab treatment in all reported patients was conducted according to Greek ethical codes and regulations, with the approval of the National Drug Administration Committee and after written informed consent was obtained from the parents. Patients' data, response, and outcome have been, retrospectively, recorded and analyzed and the Greek experience of the use of Blinatumomab for the years 2013-2015 of all the above 4, mentioned Departments is, herein, presented.

Additionally, a Greek pediatric group of 14 B-ALL patients, with refractory and/or relapsed disease, that have been diagnosed and treated before the Blinatumomab era (2000-2015) in the Department of Pediatric HematologyOncology (TAO) of "Aghia Sophia" Children's Hospital in Athens, has been retrospectively analyzed as a historical control and for clinical comparative reasons.

Blinatumomab dosage and administration. Patients received blinatumomab as a continuous intravenous infusion through a central venous catheter, in an in-patient setting, at the initial dose of $5 \mu \mathrm{g} / \mathrm{m}^{2} /$ day and dose escalation to $15 \mu \mathrm{g} / \mathrm{m}^{2} /$ day for 28 days, followed by a treatmentfree interval of 7-14 days. Responders with no CR prior to the Blinatumomab administration were planned to receive at least one additional cycle to consolidate remission status. Patients who achieved MRD remission $\left(<10^{-4}\right)$ proceeded to HSCT from haploidentical or matched sibling or unrelated stem cell donor.

Response assessment, Bone Marrow Flow Cytometry (BM-FC) evaluation, and Measurable/Minimal Residual Disease (MRD). Bone marrow (BM) was evaluated during the screening period, on day 15 of cycle 1 , and on day 29 of each cycle. Morphological remission was defined as the detection of $<5 \%$ blasts in the morphological evaluation of bone marrow smears. BM samples were investigated for leukemiaassociated immunophenotype and were assessed by multiparametric flow cytometry (FC). Flow cytometry-based MRD detection (FC-MRD) was performed as previously described [9-12]. CD19 status (positivity/negativity) was defined as surface antigen expression detected using flow cytometry upon diagnosis and relapse. In every response assessment, MRD was detected by 5-color flow cytometry, and an initial screening protocol was used with the 5-color combination of CD38-FITC, CD99-PE, CD45-ECD, CD10-PeCy5, and CD19-PeCy7. MRD response was defined as the $\geq 2-\log$ reduction of MRD value before and after the Blinatumomab administration. MRD levels $<10^{-4}$ were defined as negative.

Statistical Methods. Time to relapse was calculated as the time from blinatumomab initiation to subsequent relapse while time to event was estimated as the time from blinatumomab initiation to the first adverse event (relapse, refractory disease, secondary malignancy or death) or date of the last follow-up. Overall survival (OS) was defined as the time from blinatumomab initiation to death from any cause; for surviving patients, OS was censored at the date of last follow-up.

\section{Results}

Patients' characteristics and prior chemotherapy regimens. Between March 2015 and March 2018, 9 patients (4 females, 5 males) from 3 Greek Pediatric HematologyOncology Departments, were treated with Blinatumomab. Median age at first ALL diagnosis was 4.1 years (range 0.2-12.1 years). Upon initial leukemia diagnosis, all patients were treated according to ALLIC BFM 2009 protocol, 5/9 as Intermediate Risk (IR, 55.6\%) and 4/9 as High Risk group patients (HR, 44.4\%). Among the 9 patients, 3/9 (33.3\%) presented with initial central nervous system (CNS) involvement, 7/9 (77.8\%) were good prednisone responders (GPR) on day 8 of induction treatment and 6/9 patients (66.7\%) achieved complete remission (CR1) at the end of initial induction therapy (day 33).

At the time of Blinatumomab administration, $3 / 9$ patients (33.3\%) received Blinatumomab for refractory disease (one 
with MLL rearrangement) and 6/9 patients (77.7\%) for relapse. Among the 6 relapsed patients, 3 presented with $1^{\text {st }}$ relapse ( 1 after allo-HSCT) and 3 patients with $2^{\text {nd }}$ relapse (2 after allo-HSCT). Relapse occurrence was very early in 3 post-transplant patients and late in 3 non previously transplanted patients, with isolated bone marrow relapse site (BM) in 5 patients and combined (BM/CNS) relapse in one patient. Of all those, $7 / 9$ patients $(77.8 \%)$ had received $\geq 2$ lines of salvage treatment after relapse diagnosis and before blinatumomab administration. Details regarding patients' characteristics and chemotherapy regimens, prior blinatumomab, are shown in Table 1.

The number of Blinatumomab cycles and dosage modifications. Four patients $(4 / 9,44.4 \%)$ received 1 cycle, 4/9 patients $(44.4 \%) 2$ cycles, and only one patient $(1 / 9,11.1 \%)$ received 3 cycles of Blinatumomab (patient \#5, Table 1, Table 2). Most patients $(6 / 9,66.7 \%)$ received the pediatric dosage of stepwise escalation from 5 to $15 \mu \mathrm{g} / \mathrm{m}^{2} /$ day, while 2 patients were treated at $15 \mu \mathrm{g} / \mathrm{m}^{2} /$ day and one patient at a $5 \mu \mathrm{g} / \mathrm{m}^{2} /$ day continuous dosage schedule due to physician's decision. Of note, one patient (with MLL rearrangement) was treated with an increased dose of $45 \mu \mathrm{g} / \mathrm{m}^{2} /$ day, adapted from an adult schedule in lymphoma settings $[13,14]$, in order to overcome disease ongoing resistance (patient \#4, Table 2). Last, one patient with very early post-transplant relapse was additionally treated with concurrent donor lymphocyte infusions (DLIs) (patient \#3, Table 2).

MRD load prior to Blinatumomab treatment and MRD clearance. Median MRD load prior to $1^{\text {st }}$ Blinatumomab administration was $56.9 \%$ (range $0.025-95.0 \%$ ) and the corresponding median MRD load after the $1^{\text {st }}$ Blinatumomab cycle was $0.25 \%$ (range $0-100 \%$ ). Seven (7/9) patients presented with high MRD load (>20\%) before immunotherapy approach while Blinatumomab was administered

Table 1. Patients' characteristics and prior salvage chemotherapy regimens.

\begin{tabular}{|c|c|c|c|}
\hline $\begin{array}{l}\text { Patient } \\
\text { No }\end{array}$ & $\begin{array}{l}\text { Relapse / } \\
\text { Refractory }\end{array}$ & $1^{\text {st }}$ or $2^{\text {nd }}$ relapse & Prior chemotherapy salvage treatments \\
\hline \multirow[t]{2}{*}{$\# 1$} & Relapse & $2^{\text {nd }}$ & ALL-REZ BFM 2002 for $1^{\text {st }}$ relapse \\
\hline & & & Clofarabine/CPM/VP-16 for $2^{\text {nd }}$ relapse \\
\hline \multirow[t]{2}{*}{$\# 2$} & Relapse & $2^{\text {nd }}$ post haplo-SCT & Clofarabine/CPM/VP-16, ALLR3 for $1^{\text {st }}$ relapse \\
\hline & & & HD Ara-C/VP-16/, HR2 Block for $2^{\text {nd }}$ relapse \\
\hline \multirow[t]{2}{*}{ \#3 } & Relapse & $2^{\text {nd }}$ post allo-MSD-SCT & ALL-REZ BFM 2002 for $1^{\text {st }}$ relapse \\
\hline & & & ALLIC RELAPSE GUIDANCE 2016 (induction HI) for $2^{\text {nd }}$ relapse \\
\hline \multirow[t]{2}{*}{ \#4 } & Refractory (MLL+) & & ALLIC BFM 2009 (IA/IB/HR1/HR2/HR3), Clofarabine/VP-16/CPM, prior to $1^{\text {st }}$ Blinatumomab cycle, \\
\hline & & & ALLIC RELAPSE GUIDANCE 2016 (induction HI), 6-MP/MTX, prior to $2^{\text {nd }}$ Blinatumomab cycle \\
\hline \#5 & Refractory & & $\begin{array}{l}\text { Clofarabine/VP-16/CPM, modified HAM AML block (HD-ARAC, mitoxantrone, VCR, dexa, } \\
\text { IT), modified ALLIC IBAug (PEG, VCR, IT, imatinib) }\end{array}$ \\
\hline \#6 & Relapse (MLL+) & $1^{\text {st }}$ post allo-MUD-SCT & No \\
\hline \#7 & Refractory & & Clofarabine/CPM/VP-16, FLAG \\
\hline \#8 & Relapse & $1^{\text {st }}$ & ALLIC RELAPSE GUIDANCE 2016 \\
\hline \#9 & Relapse & $1^{\text {st }}$ & ALLIC RELAPSE GUIDANCE 2016 \\
\hline
\end{tabular}

Table 2. MRD response to Blinatumomab, FC-MRD rates, subsequent relapses and outcome.

\begin{tabular}{|c|c|c|c|c|c|c|c|}
\hline No & $\begin{array}{l}1^{\text {st }} \text { or } 2^{\text {nd }} \text { relapse } / \\
\text { refractory }\end{array}$ & $\begin{array}{c}\text { FC-MRD } \\
\text { prior to } 1^{\text {st }} \text { cycle }\end{array}$ & $\begin{array}{l}\text { FC-MRD } \\
\text { prior to } 1^{\text {st }} \text { cycle }\end{array}$ & $\begin{array}{c}\text { FC-MRD } \\
\text { post } 2^{\text {nd }} \text { cycle }\end{array}$ & $\begin{array}{l}\text { Relapse post } \\
\text { BLINA }\end{array}$ & $\begin{array}{l}\text { Treatment } \\
\text { post BLINA failure/relapse }\end{array}$ & Outcome \\
\hline$\# 1$ & $2^{\text {nd }}$ & $95.0 \%$ & $100 \%$ & & NR & Palliative therapy & DEAD \\
\hline$\# 2$ & $\begin{array}{l}2^{\text {nd }} \text { post } \\
\text { haplo-SCT }\end{array}$ & $95.0 \%$ & $98.0 \%$ & & NR & $\begin{array}{l}\text { Abroad for CAR T, not performed due } \\
\text { to renal failure and IFD }\end{array}$ & DEAD \\
\hline$\# 3$ & $\begin{array}{l}2^{\text {nd }} \text { post } \\
\text { allo-MSD-SCT }\end{array}$ & $39.9 \%$ & $0.03 \%$ & $0 \%$ & YES & $\begin{array}{l}\text { induction type IB (BFM instructions), } \\
\text { plan for CAR-T }\end{array}$ & DEAD \\
\hline$\# 4$ & $\begin{array}{l}\text { Refractory } \\
(\mathrm{MLL}+)\end{array}$ & $22.0 \%$ & $58.50 \%$ & $89.7 \%$ & NR & $\begin{array}{l}\text { IDA-FLA, 6-TG/ MTX/ VCR, } \\
\text { HR1+inotuzumab }\end{array}$ & DEAD \\
\hline \#5 & Refractory & $65.0 \%$ & $0.04 \%$ & $0 \%$ & YES, CD19- & $\begin{array}{l}\text { ALL REZ } 2002 \text { (modified Pr.II/IDA), } \\
6-\mathrm{MP} / \mathrm{MTX}\end{array}$ & ALIVE \\
\hline$\# 6$ & $\begin{array}{l}1^{\text {st }} \text { post } \\
\text { allo-MUD-SCT }\end{array}$ & $56.9 \%$ & $0.25 \%$ & $0 \%$ & NO & & DEAD \\
\hline$\# 7$ & Refractory & $65.0 \%$ & $0.25 \%$ & & YES, CD19- & Supportive care & DEAD \\
\hline$\# 8$ & $1^{\mathrm{st}}$ & $0.29 \%$ & $0 \%$ & & $\mathrm{NO}$ & & ALIVE \\
\hline$\# 9$ & $1^{\text {st }}$ & $0.025 \%$ & $0 \%$ & $0 \%$ & NO & & ALIVE \\
\hline
\end{tabular}


for deepening MRD clearance in 2 patients who had already achieved complete morphological remission $(\mathrm{CR})$ with prior chemotherapy salvage regimens (prior FC-MRD $0.025 \%$ and $0.29 \%$, respectively). Both these latter patients with prior CR achieved MRD negativity after the $1^{\text {st }}$ Blinatumomab cycle. In the whole pediatric subgroup, $6 / 9$ patients (66.7\%) achieved low MRD load $\left(<10^{-3}\right)$ after the $1^{\text {st }}$ cycle $(2 \mathrm{MRD}$ negative patients) and all MRD responders who received the $2^{\text {nd }}$ cycle further reduced their leukemic burden. FC-MRD levels and MRD clearance during the Blinatumomab approach are shown in Table 2. MRD clearance after the $1^{\text {st }}$ Blinatumomab cycle is illustrated in Figure 1.

Outcome. In our study, 6/9 patients (66.7\%) responded to the Blinatumomab approach and achieved CR after the $1^{\text {st }}$ cycle, while MRD negativity after the $1^{\text {st }}$ cycle was achieved in $2 / 2$ patients (100.0\%) with prior morphological CR. A successful bridge to HSCT was feasible in 5/9 subjects (55.6\%). Three patients $(3 / 9,33.3 \%)$ were non-responders and Blinatumomab cycles were discontinued due to disease progression; the patients received alternative salvage chemotherapy and immunotherapy approaches, including inotuzumab ozogamicin, with no response (Table 2). Median relapse-free survival (RFS) was 3.0 months (range 0.5-21.4 months) and median overall survival (OS) was 8.7 months (range 1.4-47.1 months) for the whole pediatric cohort (Table 3). MRD response ( $\geq 2-\log$ reduction of MRD value before and after the Blinatumomab administration), was associated with a median RFS/OS of 7.4/7.6 months, while lack of MRD response was associated with a median RFS and OS of 0.5 and 3.0 months, respectively.

Among the 6 patients who responded to Blinatumomab, $3 / 6$ experienced a subsequent relapse. Two relapses were CD19- and one CD19+. The first CD19- relapse was salvageable, with the patient receiving a modified Protocol II/IDA ALL REZ BFM 2002 protocol (PEG-Asparaginase combined with mitoxantrone); the patient underwent a haploidentical HSCT in CR2 and is alive, remaining in remission for 47.1 months (patient \#5, Table 2). The other two relapses postBlinatumomab administration were not salvageable, with one patient (patient \#3, Table 2) relapsing very early after haploidentical HSCT (CD19+) and the other relapsing after the $1^{\text {st }}$ Blinatumomab cycle (CD19-), with concurrent neurotoxicity grade 4 (patient \#7, Table 2 ). Both patients died due to disease progression (Table 2, Figure 2).

Of note, one patient with MLL (KMT2A) rearrangement that was refractory to immunotherapy salvage approach (Blinatumomab, inotuzumab ozogamicin), experienced leukemia switch to mixed phenotype acute leukemia (MPAL) and eventually died due to disease progression.

Toxicity, tolerance, and Blinatumomab discontinuation. Blinatumomab was generally well tolerated, with accepted low toxicity in the majority of patients. One patient developed neurotoxicity grade 4, 9 days after the $1^{\text {st }}$ Blinatumomab cycle, with multiple seizures, status epilepticus, and progressive multifocal leukoencephalopathy (PML) (patient \#7,
Table 2). Two patients had a few hour Blinatumomab administration cessations due to reversible neurological symptoms [one patient with nystagmus and one patient with 2 episodes of loss of left arm muscle strength (previous leukoencephalopathy)]. One patient developed bloodstream infection (BSI, E. coli) after the $1^{\text {st }}$ cycle of Blinatumomab, and one patient presented with an invasive fungal disease (Aspergillosis) after 3 cycles of Blinatumomab and was successfully treated with antifungal agents. In 3 patients, the Blinatumomab cycle was discontinued due to disease progression after 14, 14, and 21 days, respectively. No cytokine release syndrome (CRS) was reported and no other severe adverse events occurred due to the Blinatumomab treatment.

Historical control pediatric cohort, salvage treatment, and outcome before the Blinatumomab era. A Greek cohort of pediatric B-ALL patients diagnosed and treated before the Blinatumomab era (2000-2015) in the Department of Pediatric Hematology-Oncology (TAO) of "Aghia Sophia" Children's Hospital in Athens, (one of the 3 Departments participating in the current study), has been retrospectively analyzed for historical and comparative reasons and survival rates and outcome are, herein, presented. Among

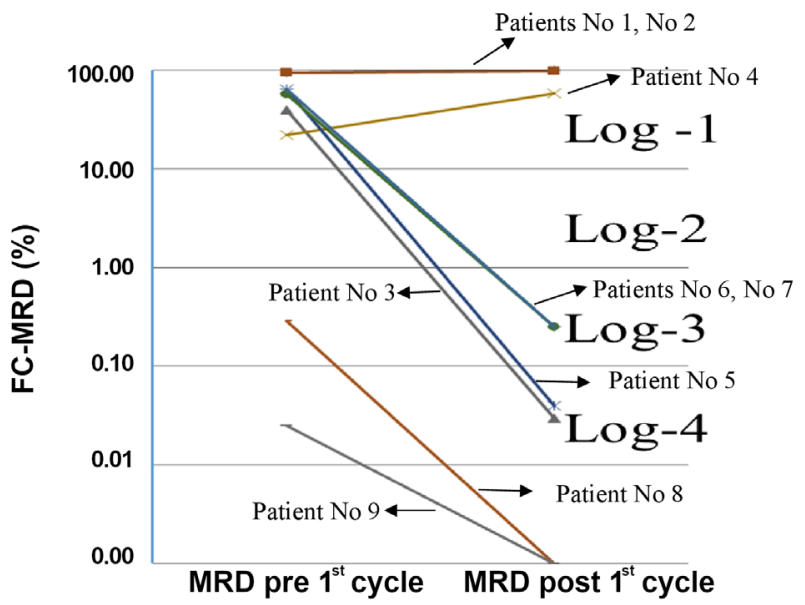

Figure 1 . MRD clearance kinetics by the $1^{\text {st }}$ Blinatumomab administration. Schematic illustration of FC-MRD values of all patients before and after the $1^{\text {st }}$ cycle of Blinatumomab. FC-MRD values are expressed as a percentage (\%) on the $y$-axis and as log-values on the right, as well. Due to similar values, some lines may be identical for 2 patients (patients No 1 and No 2, patients No 6 and No 7). FC-MRD - flow cytometry mini$\mathrm{mal} /$ measurable residual disease

Table 3. Pediatric cohort's response rates and median survival.

\begin{tabular}{ll}
\hline CR within first 2 cycles, $\mathrm{n}(\%)$ & $6(66.7)$ \\
CR after $1^{\text {st }}$ cycle, $\mathrm{n}(\%)$ & $6(66.7)$ \\
MRD response in patients with prior CR, $\mathrm{n}(\%)$ & $2(100 \%)$ \\
Non-responders & $3(33.3)$ \\
Patients who proceeded to HSCT, $\mathrm{n}(\%)$ & $5(55.6)$ \\
Median RFS, months & $3.0(0.5-21.4)$ \\
Median OS, months & $8.7(1.4-47.1)$ \\
\hline
\end{tabular}




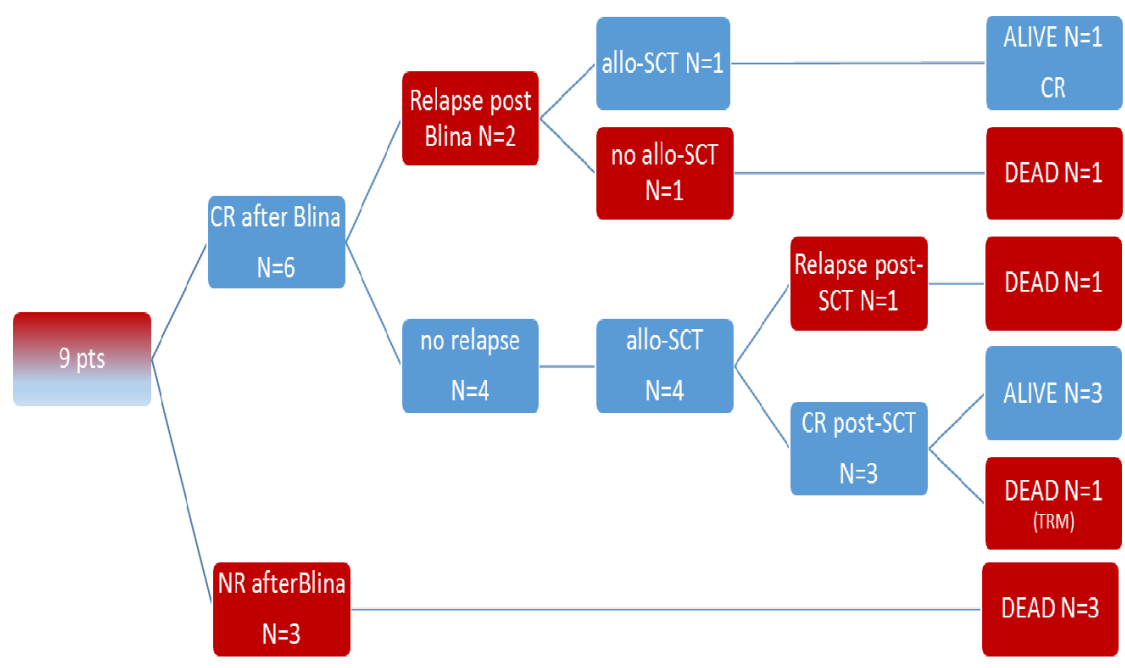

Figure 2. Schematic Blinatumomab response overview and outcome. Response and outcome of all patients after the Blinatumomab administration. $6 / 9$ patients responded to Blinatumomab cycles and in 5/9 patients an effective bridge to allo-HSCT was feasible. CR - complete remission, NR - no response, allo-SCT - allergenic Stem Cell Transplantation, TRM - transplantation-related mortality

188 B-ALL patients (116/188 males, median age 5.1 years), treated according to BFM protocols and a median follow up of 106 months, $14 / 188$ (7.5\%) patients (11/14 males) eventually relapsed (6 very early, 4 early, and 4 late relapses). The median age of relapsed patients was 9.2 years and the mean relapse time since diagnosis was 23 months (median 19.8 months, range 3.7-57.4 months). Eight (8/14) patients were treated according to the ALL-RezBFM 2002 protocol, while the remaining patients received other salvage protocols, including mainly modified ALL-RezBFM2002 protocol, IDA-FLAG or Clofarabine. Complete remission (CR2) was achieved in $42.8 \%(6 / 14)$ and only $21.4 \%$ of the patients (3/14) underwent allo-HSCT in CR2. The corresponding rates in the Blinatumomab cohort were $66.7 \%$ and $55.6 \%$, respectively. Only 4/14 patients are alive (overall survival 29\%); 6/14 died due to disease and 4/14 died due to treatment toxicity. Three out of the 4 patients with late relapse and one out of the 4 patients with early relapse are alive, while none of the six patients with very early relapse survived.

\section{Discussion}

Despite the excellent survival rates achieved in pediatric acute lymphoblastic leukemia $[9,10]$, relapsed and refractory ALL represents a distinct entity with dismal prognosis and outcome [1-9]. In this setting, immunotherapy approaches have emerged, with the Blinatumomab treatment offering pediatric patients a unique opportunity to achieve a bridge phase of complete remission in order to proceed to alloHSCT $[1-3,5,6]$.

In this report, the response rate of our heavily pretreated patients to Blinatumomab was $66.7 \%$, with a successful bridge to HSCT feasible in $55.6 \%$ of them. Over the last decade, clinical trials also comment on favorable response rates in the pediatric setting $[1-3,5,6]$, with von Stackelberg et al. [2] reporting a CR rate of $32 \%$ after two cycles of Blinatumomab. Gore et al. [1] recently published the follow-up analysis on 70 relapsed/refractory pediatric ALL patients, with a median overall survival of 7.5 months while the 24-month Kaplan-Meier estimate for overall survival was $25.0 \%$. In our pediatric cohort, median OS was 8.7 months (range 1.4-47.1 months) and survival probability by 24 months was $33.3 \%$.

The above response and survival results with the use of Blinatumomab are, in fact, superior to the ones noted in our pre-Blinatumomab era cohort, where patients were treated with the use of salvage chemotherapy regimens. Despite that, in the historical control cohort patients were mostly in the first relapse, not in a post-transplant setting and therefore not so heavily pretreated, in this setting complete remission (CR2) was achieved in $42.8 \%$ of the patients and in only $21.4 \%$ of them, an effective bridge to allo-HSCT was feasible. The corresponding rates in the Blinatumomab cohort were $66.7 \%$ and $55.6 \%$, respectively. The overall survival of the historical cohort was $29 \%$, with measurable toxicity issues, while none of the patients with very early relapse survived, indicating that none of the high-risk relapses were salvageable.

In the Blinatumomab cohort, there was a trend for prolonged survival among patients who achieved an MRD response after the $1^{\text {st }}$ Blinatumomab administration. Additionally, the 2 patients with morphological remission to whom Blinatumomab was administered for deepening MRD clearance, achieved MRD negativity after the $1^{\text {st }}$ cycle. 
It is evident that the initial MRD response to Blinatumomab may serve as a strong surrogate marker in predicting survival [15]. Furthermore; our data strongly suggest that lower MRD levels prior to the first Blinatumomab administration are associated with superior response rates and outcome, as previously described [15].

The optimal number of Blinatumomab cycles in the setting of relapsed/refractory ALL remains an open issue $[2,15]$. According to our results, Blinatumomab responders are identified from day 29 of the $1^{\text {st }}$ cycle and therefore, no further treatment seems beneficial in the case of day 29 disease refractoriness. Among initial responders, one or two more cycles of treatment could potentially induce deeper and durable remissions, but further evaluation is mandatory in order to determine whether additional cycles will actually improve overall survival.

Of note, in our Blinatumomab cohort, therapeutic maneuvers combining Blinatumomab with DLIs for very early posttransplant relapse were feasible and successful, inducing early remission. The use of inotuzumab ozogamicin $[16$, 17], showed no result in one of our patients who presented with refractory disease to Blinatumomab. The same patient (with KMT2A rearrangement) was treated with the second cycle of an increased Blinatumomab dose of $45 \mu \mathrm{g} / \mathrm{m}^{2} /$ day, adapted from an adult lymphoma schedule $[13,14]$, in order to overcome disease ongoing resistance. Increased doses of Blinatumomab, ranging up to $90 \mu \mathrm{g} / \mathrm{m}^{2} /$ day, have been evaluated in adult non-Hodgkin lymphomas [13, 14], with heterogeneous initial results; in our patient, Blinatumomab resistance was dose-independent despite dose triplication. Mechanisms of Blinatumomab resistance have long been described $[15,18,19]$, with CD19 target loss and lineage switch the most commonly reported $[18,19]$. In our study, $2 / 3$ post-Blinatumomab relapses were CD19-negative and lineage switch (MPAL) was also observed in one of our patients.

In this setting, most of the patients had already received $\geq 2$ lines of salvage chemotherapy regimens. Optimal timing of the Blinatumomab administration is, still, under investigation [15] and the IntReALL Study Group is currently evaluating the efficacy of Blinatumomab in pediatric patients with $1^{\text {st }}$ relapse, placing the investigational window randomization after the second consolidation course for High-Risk patients [20]. On top of that, the recent FDA approval of Blinatumomab in 2018, for patients with MRD+ ALL, evolves and expands the current landscape of immune therapy, from relapsed ALL, to patients with high-risk features and MRD persistence, leading to incorporating Blinatumomab into frontline therapy in future clinical trials [15].

In conclusion, our data strongly suggest that Blinatumomab may well induce deep and sustained remissions, bridging a significant percentage of relapsed or refractory ALL patients to allo-HSCT. Larger cooperative studies are required to optimize its use and facilitate the design of combination immune targeted strategies.

\section{References}

[1] GORE L, LOCATELLI F, ZUGMAIER G, HANDGRETINGER R, O'BRIEN MM et al. Survival after blinatumomab treatment in pediatric patients with relapsed/refractory Bcell acute lymphoblastic leukemia. Blood Cancer J 2018; 8; 80. https://doi.org/10.1038/s41408-018-0117-0

[2] VON STACKELBERG A, LOCATELLI F, ZUGMAIER G, HANDGRETINGER R, TRIPPETT TM et al. Phase I/Phase II study of blinatumomab in pediatric patients with relapsed/refractory acute lymphoblastic leukemia. J Clin Oncol 2016; 34: 4381-4389. https://doi. org/10.1200/JCO.2016.67.3301

[3] VON STACKELBERG A, ZUGMAIER G, HANDGRETINGER R, LOCATELLI F, RIZZARI $\mathrm{C}$ et al. A phase $1 / 2$ study of blinatumomab in pediatric patients with relapsed/refractory B-cell precursor acute lymphoblastic leukemia. J Clin Oncol 2016; 34: 4381-4389. https://doi. org/10.1200/JCO.2016.67.3301

[4] TOPP MS, STELLJES M, ZUGMAIER G, BARNETTE P, HEFFNER JR LT et al. Blinatumomab treatment after relapse in patients with relapsed/refractory B-precursor acute lymphoblastic leukemia. Leukemia 2018; 32: 562-565. https://doi.org/10.1038/leu.2017.306

[5] DERACHE A, RIALLAND F, MICHEL G, PEREL Y, GANDEMER $V$ et al. Safety and efficacy of blinatumomab used in children with B-precursor acute lymphoblastic leukemia (ALL) treated in French hematological centers. Blood 2016; 128: 5190.

[6] SCHLEGEL P, LANG P, ZUGMAIER G, EBINGER M, KREYENBERG $\mathrm{H}$ et al. Pediatric posttransplant relapse/refractory B-precursor acute lymphoblastic leukemia shows durable remission by therapy with the T-cell engaging bispecific antibody blinatumomab. Haematologica 2014; 99: 1212-1219. https://doi.org/10.3324/haematol.2013.100073

[7] HATHAWAY L, SEN JM, KENG M. Impact of blinatumomab on patient outcomes in relapsed/refractory acute lymphoblastic leukemia: evidence to date. Patient Relat Outcome Meas 2018; 9: 329-337. https://doi.org/10.2147/PROM.S149420

[8] GRUPP SA, KALOS M, BARRETT D, APLENC R, PORTER DL et al: Chimeric antigen receptor-modified T cells for acute lymphoid leukemia. N Engl J Med 2013; 368: 15091518. https://doi.org/10.1056/NEJMoa1215134

[9] AMPATZIDOU M, KELAIDI C, DWORZAK MN, POLYCHRONOPOULOU S. Adolescents and young adults with acute lymphoblastic and acute myeloid leukemia. MEMOMagazine of European Medical Oncology. 2018; 11: 47-53. https://doi.org/10.1007/s12254-017-0345-1

[10] AMPATZIDOU M, PANAGIOTOU JP, PATERAKIS G, PAPADAKIS V, PAPADHIMITRIOU SI et al. Childhood acute lymphoblastic leukemia: 12 years of experience, using a Berlin-Frankfurt-Münster approach, in a Greek center. Leuk Lymphoma 2015; 56: 251-255. https://doi.org/10.3109/1042 8194.2014.916801

[11] AMPATZIDOU M, PATERAKIS G, VASDEKIS V, PAPADHIMITRIOU SI, PAPADAKIS V et al. Prognostic significance of flow cytometry MRD log reduction during induction treatment of childhood ALL. Leuk Lymphoma 2019; 60: 258-261. https://doi.org/10.1080/10428194.2018.1471603 
[12] AMPATZIDOU M, PAPADHIMITRIOU SI, PATERAKIS G, PAVLIDIS D, TSITSIKAS K et al. ETV6/RUNX1positive childhood acute lymphoblastic leukemia (ALL): The spectrum of clonal heterogeneity and its impact on prognosis. Cancer Genet 2018; 224-225: 1-11. https://doi. org/10.1016/j.cancergen.2018.03.001

[13] VIARDOT A, GOEBELER ME, HESS G, NEUMANN S, PFREUNDSCHUH M et al. Phase 2 study of the bispecific Tcell engager (BiTE) antibody blinatumomab in relapsed/refractory diffuselarge B-celllymphoma. Blood 2016;127:1410 1416. https://doi.org/10.1182/blood-2015-06-651380

[14] HIJAZI Y, KLINGER M, SCHUB A, WU B, ZHU M et al. Blinatumomab exposure and pharmacodynamic response in patients with non-Hodgkin lymphoma (NHL). Curr Clin Pharmacol 2018; 13: 55-64. https://doi.org/10.2174/1574884 713666180518102514

[15] CURRAN E, STOCK W. Taking a "BiTE out of ALL": Blinatumomab approval for MRD-positive ALL. Blood 2019; 133: 1715-1719. https://doi.org/10.1182/blood-2018-12-852376

[16] KANTARJIAN H, THOMAS D, JORGENSEN J, JABBOUR E, KEBRIAEI $P$ et al. Inotuzumab ozogamicin, an anti-CD22-calecheamicin conjugate, for refractory and relapsed acute lymphocytic leukaemia: A phase 2 study. Lancet Oncol 2012; 13: 403-411. https://doi.org/10.1016/S14702045(11)70386-2
[17] RAETZ EA, CAIRO MS, BOROWITZ MJ, LU X, DEVIDAS $M$ et al. Re-induction chemoimmunotherapy with epratuzumab in relapsed acute lymphoblastic leukemia (ALL): Phase II results from Children's Oncology Group (COG) study ADVL04P2. Pediatr Blood Cancer 2015; 62: 11711175. https://doi.org/10.1002/pbc. 25454

[18] MEJSTRÍKOVÁ E, HRUSAK O, BOROWITZ MJ, WHITLOCK JA, BRETHON B et al. CD19-negative relapse of pediatric B-cell precursor acute lymphoblastic leukemia following blinatumomab treatment. Blood Cancer J 2017; 7: 659. https://doi.org/10.1038/s41408-017-0023-x

[19] RAYES A, MCMASTERS RL, O'BRIEN MM. Lineage Switch in MLL-Rearranged Infant Leukemia Following CD19-Directed Therapy. Pediatr Blood Cancer 2016; 63: 1113-1115. https://doi.org/10.1002/pbc.25953

[20] Phase 3 Trial of Blinatumomab vs Standard Chemotherapy in Pediatric Subjects With HR First Relapse B-precursor ALL. ClinicalTrials.gov Identifier: NCT02393859. https://clinicaltrials.gov/ct2/show/NCT02393859 